\title{
A HIGH POWER DIODE LASER (HPDL)-BASED TECHNIQUE FOR THE BONDING OF COMPOSITE PATCHES TO ALUMINIUM ALLOYS ON VARIOUS MILITARY AIRCRAFT
}

\author{
J. Lawrence
}

Manufacturing Engineering Division, School of Mechanical \& Production Engineering, Nanyang Technological University (NTU), Nanyang Avenue, Singapore 639798.

\section{Correspondence}

Dr. Jonathan Lawrence,

Manufacturing Engineering Division,

School of Mechanical \& Production Engineering,

Nanyang Technological University (NTU),

Nanyang Avenue,

Singapore 639798.

Tel : (65) 67905542

Fax : (65) 67911859

email : mjlawrence@ntu.edu.sg 


\begin{abstract}
A rapid, effective and repeatable technique for repairing the damaged skins of various military aircraft, both fixed and rotary winged, using high power diode laser (HPDL) radiation is described herein. The HPDL beam was traversed across the surface of an APC-2 repair patch, thereby melting a thermoplastic adhesive placed in between the repair patch and an Alclad substrate, consequently bonding the repair patch to the Alclad substrate. When subjected to single lap shear tests, the shear strength of the bond generated with the HPDL radiation was $47.8 \pm 4.7 \mathrm{MPa}$, compared to $32.4 \pm 3.7$ MPa for the induction welded samples. When subjected to the Boeing wedge test, the HPDL samples had a 1 hour crack growth rate that was rated as very good $(1.9 \pm 0.5 \mathrm{~mm} / \mathrm{h})$; for the induction welded samples the 1 hour crack growth rate that was rated as good $(2.7 \pm 1.2 \mathrm{~mm} / \mathrm{h})$. Of great significance was processing time achieved with the HPDL, which was reduced from 11.75 minutes when employing induction welding to 2.75 minutes with the HPDL. Moreover, the use of HPDL radiation has been shown in this work to be an effective means for bonding that is superior to its contemporary counterparts.
\end{abstract}

Key words: High power diode laser (HPDL); Aircraft; Repair 


\section{INTRODUCTION}

One of the most intractable problems confronting modern air force ground crew is the effective and rapid repair of aircraft skins. This problem is compounded many fold when the ground crew are faced with having to make the necessary repairs in the field. Typically, ground crew are required to repair holes in the outer skin of various parts of a number of different types of aircraft which are caused by bullets and shrapnel during combat. This work describes a feasible solution to this possibly debilitating problem through the deployment of a HPDL-based technique to bond composite patches over these holes and thus render the aircraft airworthy again in the shortest possible time.

The options currently available to ground crew for carrying out such repairs in the field are extremely limited [1]. Moreover, none are rapid; a crucial factor in combat conditions. Such methods are usually centred on the use of bolted or riveted metallic patches [1]. Although these metallic patches are often reasonably effective, they are inefficient due to the counterproductive generation of stress concentrators by the fastener holes [2]. In contrast, bonded composite patches would distribute loads more evenly and their fixing would not generate stress concentrators [2-5]. For this reason, along with reasons such as high specific strength, stiffness, fatigue resistance and corrosion resistance, composite patches are used extensively for the repair of aluminium aerospace structures [6].

These composite patches are commonly bonded to the damaged aluminium substrate with an epoxy structural adhesive. Owing to the problems of bonding process repeatability and mixing attendant with two-part formulations, these epoxy adhesive systems have been developed in the form of onepart films [1]. Still, one-part epoxy adhesives suffer from short shelf-life and, as Soy et al. [7] discovered, consistency in terms of performance (fatigue life and stress resistance) is difficult to achieve. In addition, even though Phung et al. [8] achieved improvements in the strength of the aluminium/epoxy bonding joint by modification of the interphase with pre-treatments including selfassembly of phosphoric acid mono alkyl, the improvements were slight. Another problem with epoxy adhesives is moisture absorption from the atmosphere. In work conducted by Johnsen et al. [9] into the effect of pre-bond moisture on epoxy-bonded aluminium showed that significant decreases in crack growth resistance were achieved when bonding was conducted in a low relative humidity atmosphere. To counter these shortcomings, advanced thermoplastic adhesives have recently been developed that are tough, possess improved hot/wet resistance, do not absorb significant amounts of water, have unlimited shelf-life and cost less to process [9].

Current methods developed for bonding composite patches to aluminium alloy surfaces require long bonding times at fairly low temperatures. Resistance implant welding is a method for rapidly heating and melting the composite at the bonding interface by passing an electric current through a resistive element placed at the interface. Maguire [10] obtained a single lap shear strength of $24 \mathrm{MPa}$ for bonding APC-2, a PEEK/graphite composite, by passing d.c. current through two rows of carbon fibre 
placed at the interface along with a PEEK interlayer. Induction welding is based on the principal of a magnetic field generating eddy currents within a conductor. Electrically conductive materials are heated resistively by small-scale current loops which are formed in the material in response to the magnetic field. These current loops actually penetrate below the surface of the material to a depth known as the 'skin depth'. It is a non-contact form of heating that operates at a very high speed and one in which pressure can be readily applied, by using a glass-ceramic pressure plate [11]. Furthermore, the coil may be readily placed on one-side of the joint and this could be useful for field repair. On the other hand, Benatar and Gutowski [12] used a 'susceptor layer' near the interface of a polymer containing nickel-coated carbon fibres to effect localised heating concentrated at the interface On a different attempt, Kodokian [13] used fine particles of a ferromagnetic material, such as nickel or iron, embedded in a polymer interlayer as the 'susceptor'. Yet in both of these two cases, a 'contaminant' was introduced to the interface which has the potential to lead to adverse effects.

\section{EXPERIMENTAL PROCEDURES}

\section{A. Materials preparation}

The substrate used in this work was the now common aluminium aerospace alloy Alclad 2024-T. The Alclad was received as a rectangular billet with dimensions of $25 \mathrm{~mm}$ x $100 \mathrm{~mm}$ x $5 \mathrm{~mm}$. The repair patch adhered to the Alclad substrate was a composite of graphite in a polyetheretherketone (PEEK) thermoplastic matrices termed APC-2. The APC-2 repair patch was moulded from 12 layers of prepreg with the lay-up (0/0/90/90/0/90). The APC-2 repair patch was received as a square measuring $25 \mathrm{~mm}$ x $50 \mathrm{~mm}$. The thickness of the APC-2 repair patch cannot be given for commercial reasons. A specially designed thermoplastic was used as the adhesive. The melting temperature of the thermoplastic is $250^{\circ} \mathrm{C}$. Save for its breadth and length dimensions of $25 \mathrm{~mm}$ x $25 \mathrm{~mm}$, further details of the thermoplastic cannot be released due to commercial sensitivity.

The received Alclad was cleaned in accordance with the British MOD standard 03-2/1 Method O [14]. This involved cleaning the surface with acetone, 1,1,1 trichloroethane and then alkaline degreaser before being chromatic acid etched at 60 to $65^{\circ} \mathrm{C}$ for 30 minutes. After the chromatic acid etch the Alclad was rinsed under tap water for 7 minutes and then air dried at $25^{\circ} \mathrm{C}$ in normal atmospheric conditions for 30 minutes.

\section{B. Laser processing arrangement}

As one can see from Fig. 1, the samples were placed in a vacuum box (which in the field, the vacuum could be provided by a material with the capability of adhering to the contoured aircraft skin so as to provide a sealed edge and therefore allow vacuuming, as well as being transparent to the HPDL beam). Prior to HPDL radiation treatment the box was vacuumed to 2 torr so as to cause the glass 
window which was free to move vertically to press the APC-2 repair patch onto the Alclad substrate and ensure that the cured thermoplastic adhesive was of a narrow $(<0.2 \mathrm{~mm})$, even cross-section that was free of trapped air pockets. The laser used to conduct the forming experiments was the contemporary $2.5 \mathrm{~kW}$ HPDL (DL-025; Rofin-Sinar, GmBh), emitting at $940 \mathrm{~nm}$. The defocused multimode HPDL beam was fired onto the surface of the samples through the glass window of the vacuum box in a rectangular beam configuration of $6 \mathrm{~mm}$ width and $4 \mathrm{~mm}$ length. The HPDL output powers ranged from 1.5 to $2.3 \mathrm{~kW}$. The beam was traversed across the surface of the APC-2 repair patch by means of mounting the assembly head onto the z-axis of a 3-axis computerised numerical control (CNC) gantry table. The defocused HPDL beam was thus fired across the surface of the surface of the APC-2 repair patch by traversing the vacuum box containing the samples beneath the HPDL beam using the $\mathrm{x}$ - and $\mathrm{y}$-axis of the CNC gantry table at speeds of 120 to $840 \mathrm{~mm} / \mathrm{min}$. The HPDL beam was scanned across the width of the APC-2 repair patch $(25 \mathrm{~mm})$ five-times by overlapping the HPDL beam by $1 \mathrm{~mm}$. The HPDL beam path is shown schematically in Fig. 2. No melting of the surface of the APC-2 repair patch was observed on any of the samples either during or at the end of the HPDL bonding. Following interaction with the HPDL beam, the APC-2 repair patch bonded to the Alclad substrate was allowed to cool in air at $25^{\circ} \mathrm{C}$ under normal atmospheric conditions for 4 hours, whereupon testing was commenced immediately.

\section{Joint testing arrangements}

For comparison purposes, samples were made up with the same materials and in the same configuration using the well established technique of induction welding. After the induction welding was completed, the samples were left for 24 hours to condition before testing was began. The joints of both the HPDL beam bonded and induction welded samples were subjected to the same two standard aviation tests: the single lap shear test (ASTM D1002-01) [15] and the Boeing wedge test (ASTM D3762-79) [16]. The component configuration of the APC-2 repair patch, the Alclad substrate and the thermoplastic adhesive to produce samples for the single lap shear test and the Boeing wedge test are shown in Fig. 3 and Fig. 4 respectively.

To perform the single-lap shear tests, the protruding sides of APC-2 repair patch and the Alclad substrate were placed in the opposing jaws of an Instron testing machine. A force was then applied to move the jaws in opposite directions at a rate of $5 \mathrm{~mm} / \mathrm{min}$ until complete separation occurred.

The wedge used in the tests was fabricated from stainless steel. The wedge had dimensions of $1 \mathrm{inch}$ long $\mathrm{x} 1 \mathrm{inch}$ wide and was 0.125 inches thick. One end of the wedge was tapered from a sharp point out to the initial thickness of the wedges of 0.125 inches, giving a taper length of 0.25 inches. In order allow space for the stainless steel wedge to enter between the APC-2 repair patch and the Alclad substrate, the thermoplastic adhesive sized so as to leave a standard gap at the end of the sample after HPDL beam bonding of $25 \mathrm{~mm}$. The stainless steel wedge was then driven inwards into the joint with 
several light taps with a hammer to pre-crack the unbonded end of the samples. The initial crack length was noted and thereafter at regular intervals the crack propagation was monitored.

\section{RESULTS AND DISCUSSION}

\section{A. Single lap shear test results}

The single lap shear strengths of the bonds produced with the HPDL beam process and with induction welding are given in Fig. 5. For additional comparison, the results for samples produced using resistive implant welding with the same materials as those investigated in this study by Chan-Park et al. [17] are also given in Fig. 5.

It is evident from Fig. 5 that the bond generated with HPDL radiation displayed a higher single lap shear strength than the resistive implant welded bond and was significantly higher than the bond produced with induction welding, $47.8 \pm 4.7 \mathrm{MPa}$ compared to $32.4 \pm 3.7 \mathrm{MPa}$ and $41.7 \mathrm{MPa}$ respectively. One possible explanation for this difference in performance is that with induction welding, only heated the Alclad substrate preferentially but not the APC-2 repair patch. As a result, fusion bonding on the underside of the APC-2 repair patch becomes dependant exclusively on the conduction of heat from the Alclad to the thermoplastic adhesive interlayer, then to the APC-2 repair patch. Consequently the bond formed will not be flawless. A visual inspection of the separated pieces of the joint confirmed this; with small particles of the APC-2 repair patch being observed on the pieces of the thermoplastic adhesive that remained on the Alclad. This is indicative of cohesive failure within the aluminium oxide layer. However, the small amounts of APC-2 seen signify mainly cohesive failure within the thermoplastic adhesive. This was not the case when forming of the bond was carried out with the HPDL beam. This was because the heating and melting of the thermoplastic adhesive was the result of direct heat conduction through the APC-2 repair patch. Thereafter, a small amount of heat was conducted to the Alclad substrate, thereby allowing the thermoplastic adhesive to bond more fully and evenly with both materials and produce a stronger bond. In the case of resistive implant welding, Chan-Park et al. [17] determined that the use of a resistive implant ensured that the bond line heated up directly to create a good bond. The work revealed that for the resistance implant bonding, failure occurred primarily through tensile failure in the implant and delamination of the implant from the APC-2 repair patch. So, although the bond produced will be superior to that achieved with induction welding, it will nevertheless be inherently weaker than the bond produced with HPDL radiation.

\section{B. Boeing wedge test results}

The results of the Boeing wedge tests for the bonds produced by induction welding and HPDL radiation are plotted in Fig. 6 . The results are normalised as they only show the length of the cracks 
propagated following pre-cracking of the bonds with the wedge. From Fig. 5 it was possible to determine the 1 hour propagation rate of the cracks in the bonds generated with induction welding and HPDL radiation. Table 1 gives the acceptable criteria ratings for joint durability [1] and Table 2 gives the full details of the cracks propagated.

As one can see from Table 2, when subjected to the Boeing wedge test, the samples bonded with HPDL radiation had a 1 hour crack growth rate of $1.9 \pm 0.5 \mathrm{~mm} / \mathrm{h}$, which, according to Table 1 this growth rate is deemed to be very good. For the induction welded samples the 1 hour crack growth rate that was rated as good, being $2.7 \pm 1.2 \mathrm{~mm} / \mathrm{h}$.

Yet again it is clear from these results that the HPDL beam bonding process is superior to the techniques currently available, albeit marginally in this case. This enhanced performance is again the result of the more consistent melting of the thermoplastic adhesive across its entire section, which in turn promotes fuller bonding to both the APC-2 repair patch and the Alclad substrate, not just the APC-2 repair patch as is the case with induction welding.

\section{Thermal history}

Perhaps one of the most crucial factors that needs to be taken into account when considering the repair of battle damaged aircraft is the speed of the repair. To this end the thermal history of the bonds produced with induction welding and the HPDL beam was recorded in terms of the heating rate. For both induction welded and HPDL beam bonded samples the thermocouples were placed between the Alclad and the thermoplastic adhesive. aluminium and the APC-2 repair patch. To provide further comparison, the thermal history for samples produced using resistive implant welding with the same materials as those investigated in this study by Chan-Park et al. [17] are also given in Fig. 6. In this case a thermocouple was inserted between the implant and the APC-2 repair patch laminate. The thermal histories of the three methods are given in Fig. 7.

As is evident from Fig. 7, the resistive implant welding technique is much slower that either the HPDL beam bonding method or the induction welding technique at reaching the $250^{\circ} \mathrm{C}$ melting temperature of the thermoplastic adhesive. Indeed, whereas the bond line of the HPDL beam bonding method and the induction welding technique reached $250{ }^{\circ} \mathrm{C}$ in around 1 minute, the resistive implant welding technique took around 6 minutes.

Although the times taken to reach the $250{ }^{\circ} \mathrm{C}$ mark were similar for the HPDL beam bonding and induction welding techniques, the actual times to complete the bonding were very different. The processing time achieved with HPDL radiation was to 2.75 minutes, compared with 11.75 minutes when employing induction welding. This is due to the fact that the heating is too localised in the induction welding technique, a problem that is avoided when using the HPDL beam owing to that fact a wide beam that is scanned over the surface of the APC-2 repair patch is utilised. 
Of particular importance is the fact that the temperature keeps rising for the induction welding and resistive implant welding techniques. Indeed, the temperature recorded was over $300^{\circ} \mathrm{C}$ with induction welding which will subsequently result in damage to the Alclad substrate. This is not the case for the bonds produced with HPDL radiation due to the scanning of the beam.

\section{CONCLUSIONS}

A technique for repairing the damaged skins of various military aircraft that is rapid, effective and repeatable, using a high power diode laser (HPDL) beam has been demonstrated. Using the HPDL beam, a thermoplastic adhesive interlayer was melted forming a joint between an APC-2 repair patch and an Alclad substrate. When subjected to various standard aerospace tests, the HPDL radiation generated bonds were found to be superior to those produced using more established techniques. In single lap shear tests, the shear strength of the bond generated with HPDL radiation was $47.8 \pm 4.7$ $\mathrm{MPa}$, compared to $32.4 \pm 3.7 \mathrm{MPa}$ for induction welded samples and published strengths of $41.7 \mathrm{MPa}$ for restive implant welded samples. When subjected to the Boeing wedge test, the HPDL beam samples had a 1 hour crack growth rate that was rated as very good $(1.9 \pm 0.5 \mathrm{~mm} / \mathrm{h})$; for the induction welded samples the 1 hour crack growth rate that was rated as good $(2.7 \pm 1.2 \mathrm{~mm} / \mathrm{h})$. Of great significance was the processing time achieved with the HPDL beam, which was reduced from 11.75 minutes when employing induction welding to 2.75 minutes with HPDL radiation. These results demonstrate that the HPDL beam-based technique is a feasible solution to the possibly debilitating problem of grounded aircraft in a combat context by rendering the aircraft airworthy again in a very short time. What is more, the nature of the HPDL lends itself to battle field deployment. Moreover, the HPDL has been shown in this work to be a tool for bonding that is superior to its contemporary counterparts. It is, therefore, distinctly possible that even stronger bonds could be achieved with HPDL radiation if different adhesives were used.

\section{REFERENCES}

1. L.J. Kelly, In Bonded Repair of Aircraft Structures (Eds.) A.A. Baker \& R. Jones, Dordrecht: Nijhoff Publishers, pp. 1-46 (1988).

2. C.L. Ong and S.B. Shen, Theoretical Appl Fracture Mechanics, 16, 145-153 (1991).

3. C.L. Ong and S.B. Shen, Int. J Adhesion Adhesives, 12, 19-26 (1992).

4. Z. Marioli-Riga, D. Xenos and C. Vrettos, Appl Composite Mater, 11, 191-203 (2004).

5. K.H. Chung, W.H. Yang and S.P. Heo, KSME Int. J, 16, 599-608 (2002).

6. A.R. Kumar and S.A. Hakeem, Composite Struct, 49, 285-292 (2000).

7. U. Soy, M. Caliskan and F. Findik, Sci Eng Composite Mater, 11, 69-77 (2004). 
8. L.H. Phung, H. Kleinert, I. Jansen, R. Hassler and E. Jahne, Macromolecular Symp, 210, 349-358 (2004).

9. B.B. Johnsen, F. Lapique, A. Bjorgum, J. Walmsley, S.S. Tanem and T. Luksepp, Int J Adhesion Adhesives, 24, 183-191 (2004).

10. D.M. Maguire, $J$ Adv Mater, 25, 11-20 (1989).

11. J. Border and R. Salas, Proceeding of the $34^{\text {th }}$ International SAMPE Symposium, Miami, FL, USA, May 1989, pp. 258-266 (1989).

12. A. Benatar and T.G. Gutowski, J Adv Mater, 18, 34-41 (1986).

13. G.K.A. Kodokian, US Patent 5,340,428 (1994).

14. British Ministry of Defence Standard 03-2/1 Method O: Preparation of aluminium substrates (1983).

15. ASTM D1002-01: Standard Test Method for Apparent Shear Strength of Single-Lap-Joint Adhesively Bonded Metal Specimens by Tension Loading (2003).

16. ASTM D3762-79: Adhesive Bonded Durability of Aluminium (Wedge Test) (1979).

17. M.B. Chan-Park, H.S. Ngew, D.C.F Yip, C.J. Er and S.W. Zee, J Adv Mater, 33, 52-61 (2001). 


\section{List of Figs.}

Fig. 1. Schematic diagram of the HPDL beam processing arrangement.

Fig. 2. Schematic representation of the HPDL beam path over the surface of the APC-2 repair patch.

Fig. 3. Component part configuration for the single lap shear test.

Fig. 4. Component part configuration for the Boeing wedge test.

Fig. 5. Single lap shear strength for the bonds produced with the HPDL beam, induction welding and resistive implant welding.

Fig. 6. Normalised crack length for the Boeing wedge test on the bonds produced by induction welding and HPDL radiation.

Fig. 7. Comparison of the thermal histories for HPDL beam bonding, induction welding and resistive implant welding. 
Fig. 1

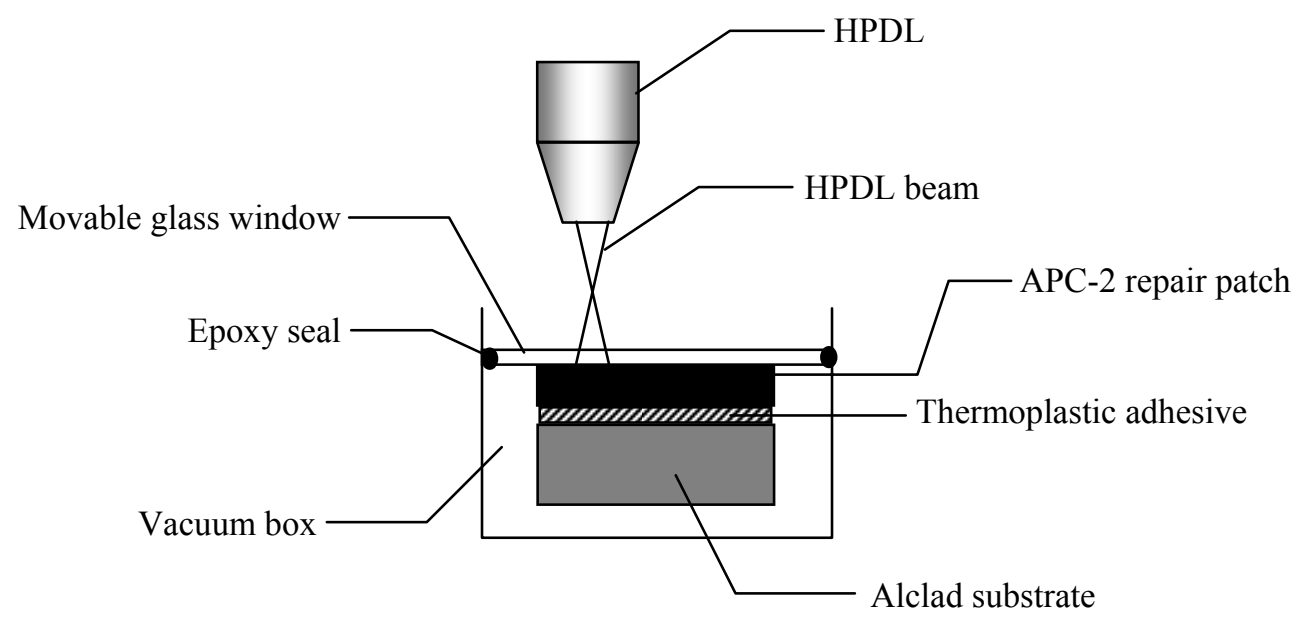


Fig. 2

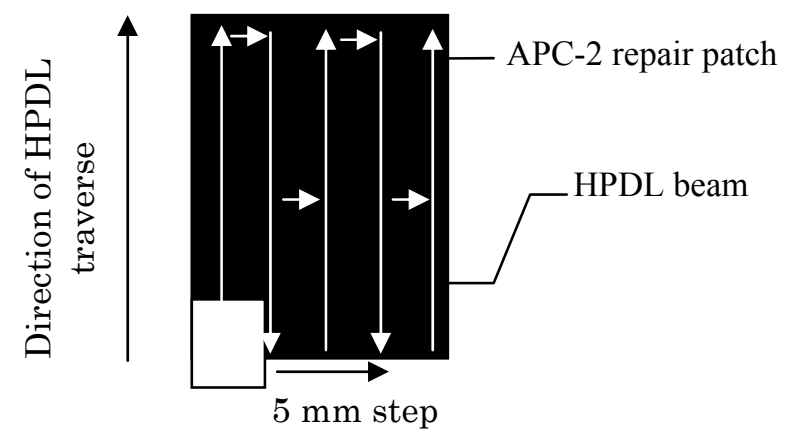


Fig. 3

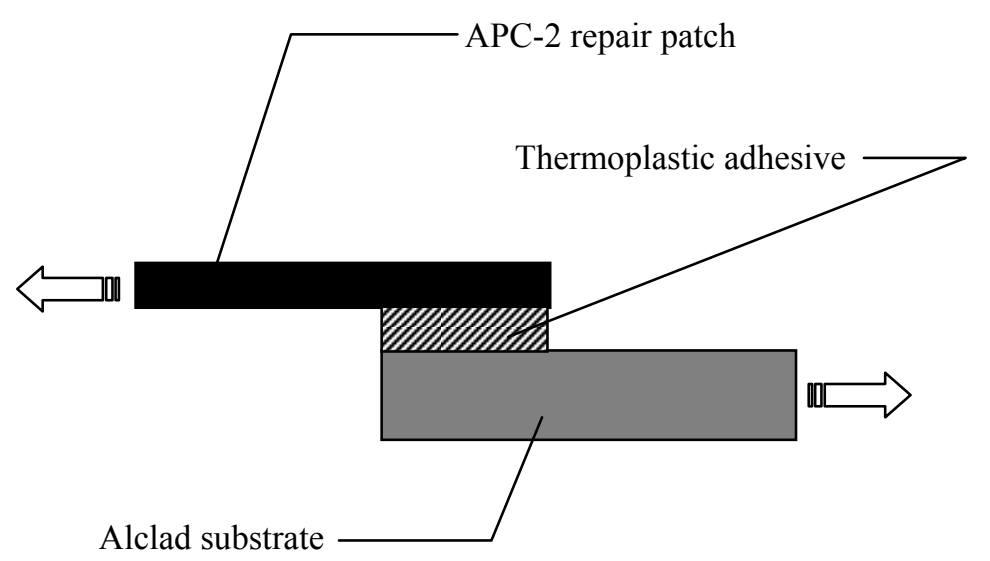


Fig. 4

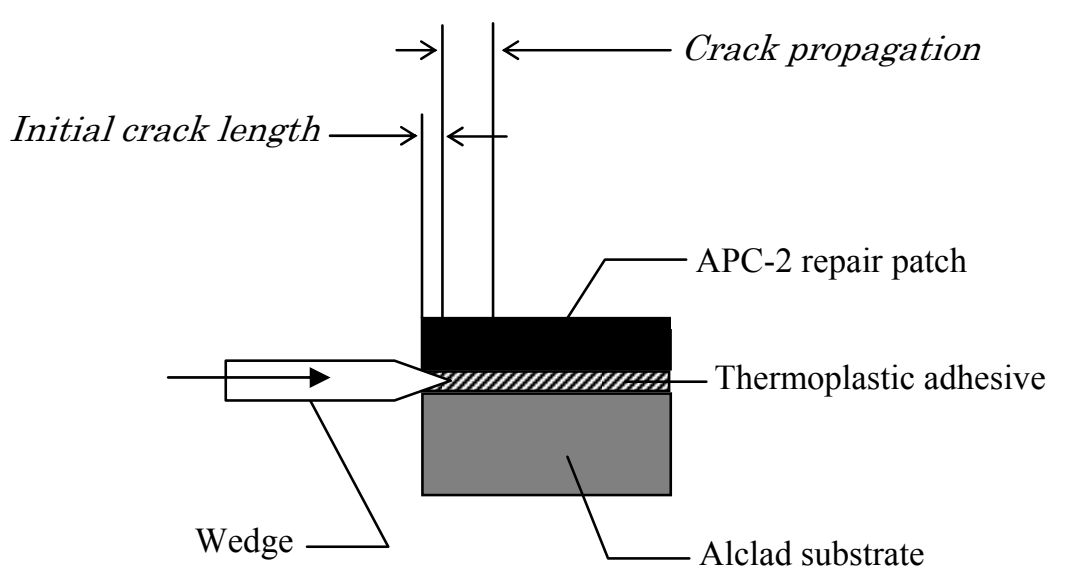


Fig. 5

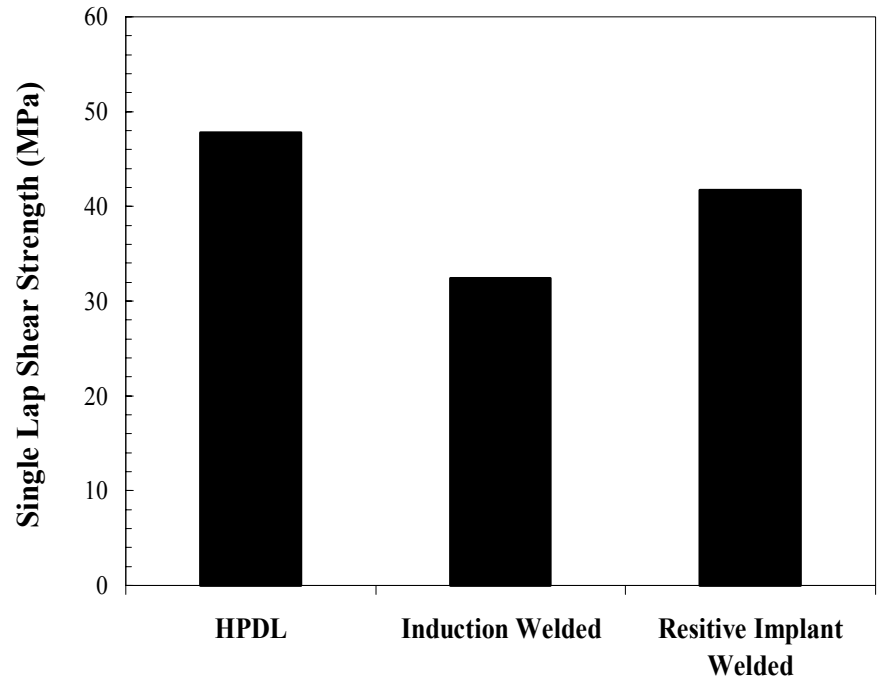


Fig. 6

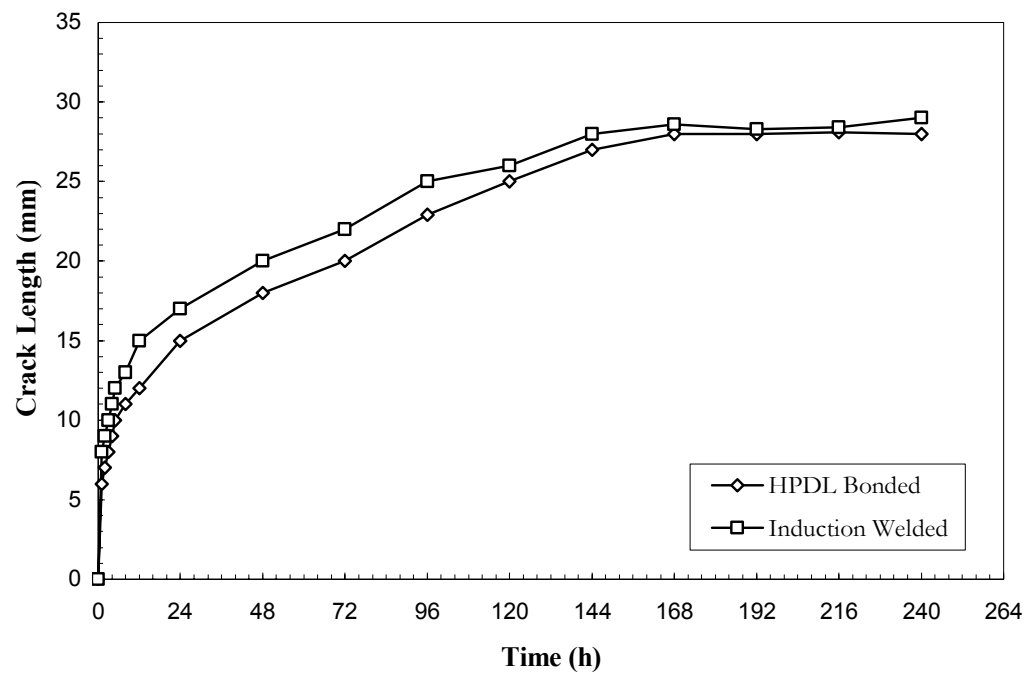


Fig. 7

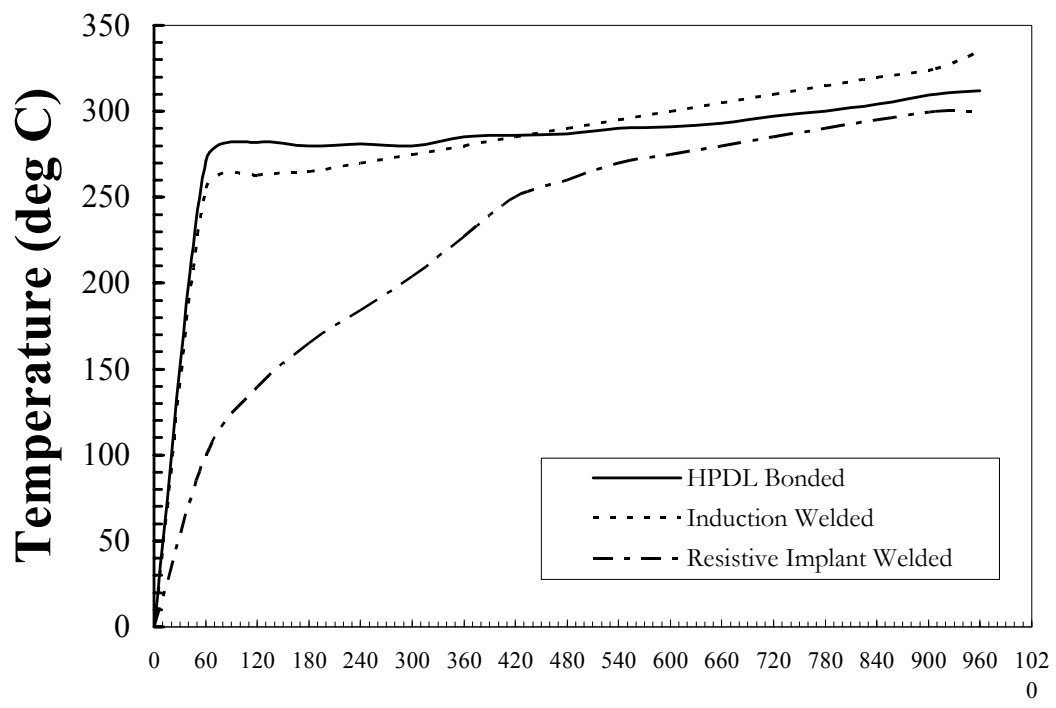

Time (s) 


\section{List of Tables}

Table 1. Acceptable criteria ratings for the Boeing wedge test [1].

Table 2. Characteristics of the cracks propagated in bonds produced by HPDL radiation and induction welding. 
Table 1.

\begin{tabular}{ll}
\hline Crack growth $(\mathbf{m m} / \mathbf{h})$ & \multicolumn{1}{c}{ Rating } \\
\hline 0.000 to 2.540 & Very good \\
2.550 to 6.000 & Good \\
6.001 and above & Marginal to unacceptable \\
\hline
\end{tabular}


Table 2.

\section{Bond Type}

Crack Characteristics Induction Welding HPDL Radiation

Initial crack length $(\mathrm{mm})$

Crack growth $(\mathrm{mm} / \mathrm{h})$

73.24 .7

$62.8 \pm 3.0$

Criteria rating

$2.7 \pm 1.2$

$1.9 \pm 0.5$

Good

Very good 